\title{
La dialéctica no es la sofística. Teeteto aprende esto en El sofista (segunda parte) $)^{1}$
}

HANS-GEORG GADAMER

TRADUCCiÓn DE MARÍA TERESA PADILla LONGORIA

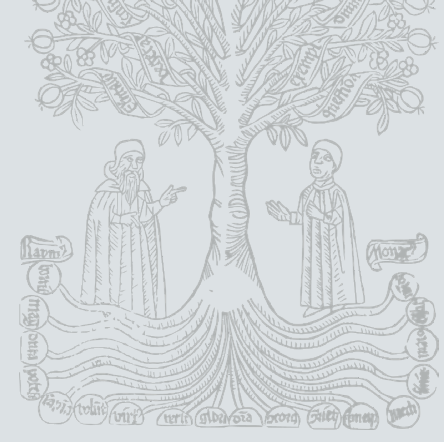

[Continuación de la primera parte, publicada en Theoría, (39), 192-196. https://doi.org/10.22201/ffyl.16656415p.2020.39.1400]

[342] El proyecto neokantiano se sitúa en un contexto que va mucho más lejos y que determinó la interpretación filosófica de Platón, a saber, en el ámbito filosófico de acción del idealismo alemán: el último gran intento de la modernidad por conciliar la herencia de la metafísica con las ciencias empíricas modernas. Ya Fichte, y más aún Schelling y Hegel, concordaron en que la deducción de los conceptos básicos, de los conceptos apriorísticos del intelecto, por fin alcanzará el a posteriori de la experiencia y consolidará su verdad, por así decirlo, de manera apriorística. También Hermann Cohen efectuó, de esa manera, la adaptación a la investigación moderna, declarando la construcción del objeto de la experiencia, gracias al método infinitesimal, como la excelencia y la confirmación propias del idealismo, y Natorp creyó leerlo entre líneas en Platón. El idealismo transcendental tuvo consecuencias a gran escala para toda la comprensión de la filosofía de Platón. ${ }^{2}$ [343] Seducido por Aristóteles, así se percibió el problema decisivo de la teoría de las ideas de Platón, en la participación de lo particular en la idea. Mi tesis es la siguiente: esto, de ninguna manera, es un problema platónico, sino un prerrequisito.

\footnotetext{
1 Traducción del artículo "Dialektik ist nicht Sophistik. Theätet lernt das im Sophistes" [1990] (Gesammelte Werke 7: Griechische Philosophie III, Tübingen, J. C. B. Mohr (Paul Siebeck): 11991/21999, S. 338-342.

${ }^{2}$ No voy a mencionar aquí ni las contribuciones de la escuela histórica (desde Schleiermacher hasta Wilamowitz) ni tampoco la investigación extranjera correspondiente, y remito al informe colectivo de E. M. Manasse (suplementos 1 [1957], 2 [1961], y 7 [1976] de la Revista Filosófica)
} 
Platón siempre consideró la participación de lo particular en la idea como algo evidente que hace que la aceptación de las ideas, después de todo, sea razonable. Por tal motivo, él fue bastante natural en la caracterización lingüística de esta relación, si él llamaba a la relación de lo particular con lo general presencia, compañía, participación, entrelazamiento, mezcla o como la haya llamado (cf. Fedón 100d5 ss.).

Si se tiene en mente que Platón, a quien Aristóteles cuenta deliberadamente entre los pitagóricos tiene a la vista el paradigma matemático, entonces, es para él, el objeto de conocimiento [tanto] lo uno y [como] lo múltiple ( $\tau \tilde{\alpha} \lambda \lambda \alpha)$ y no lo particular. En efecto, es palmario que los objetos matemáticos no requieren, de ninguna manera, un fundamento específico de la multiplicación. Más aún: es como Platón, por ejemplo, en el Sofista se refiere a un concepto tan formal como el de ě́ॄpov que está distribuido en lo particular. La

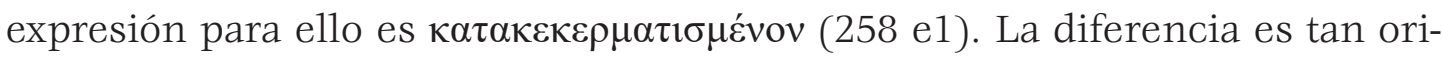
ginal como la unidad, y esto incluso se trasluce a través de la descripción aristotélica de los dos principios del uno y de la dualidad. Fue primero Aristóteles y su crítica de la matematización ${ }^{3}$ de la realidad que él vio en Platón y la criticó todavía en la manera mítico-descriptiva de la Física del Timeo, a través de la cual él apenas llegó a elevar como problema, la participación de lo particular en lo universal.

Cuán poco aludió Platón a esto resulta primordialmente de la sección introductoria del diálogo Parménides. Ahí se plantea la pregunta acerca de cómo la apariencia podrá participar en la idea, y todas las respuestas del joven Sócrates son reducidas ad absurdum. En contraposición, estas preguntas se dejan de lado, aparentemente como insignificantes, por el viejo Parménides mismo. El único sentido del problema de la methexis consiste en la relación de las ideas entre sí. Esto, y exclusivamente esto, es el verdadero problema de la participación en Platón. Con ello es patente que las explicaciones de la dialéctica platónica ensayadas por el neokantismo hacen caso omiso en un punto decisivo de la cuestión. Nicolai Hartmann desarrolló en un agudo estudio una teoría de la methexis en progresión descendente. ${ }^{4}$ La meta disimulada de Hartmann residió en querer traspasar incluso el límite que representa indis-

\footnotetext{
${ }^{3}$ N. de la T.: Por matematización se entenderá el giro hacia el método matemático en la investigación científica. No hay que confundirlo con el vocablo matematismo, que hace referencia a la tendencia a reproducir los procesos de la realidad de la ciencia, principalmente la lógica, en fórmulas matemáticas. ${ }^{4}$ La lógica del ser de Platón (1909), obra en la que Natorp, en la segunda edición (1921), cita expresamente la teoría de las ideas de Platón.
} 


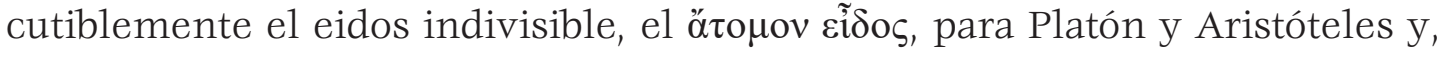
con ello, [344] para la dialéctica y la filosofía. Los neokantianos debieron reinterpretar a Kant en el sentido del idealismo postkantiano, como se pone de manifiesto en la famosa formulación de Natorp. Natorp pudo ver el único sentido de la "cosa en sí" solamente en el hecho de que ella representa la tarea interminable de determinar el objeto. Corresponde a las ciencias empíricas de la época moderna que el acercamiento a lo particular hasta la determinación plena y el dominio de la realidad empírica constituye el verdadero sentido directriz de la cognición. Pero para alguien que parte íntegramente de la dimensión del discurso y del lenguaje, como Platón y Aristóteles, es evidente que, en verdad, siempre es, tan sólo, un eidos, el eidos indivisible donde el proceso de la especificación llega, necesariamente, a su fin. Bajo la predisposición del concepto moderno del empirismo y de la ciencia, los "idola fori" no tienen, por el contrario, ningún valor cognoscitivo, porque, para ellos, lo particular concreto debe ser lo verdaderamente conocido.

De forma que la conocida pregunta de Plotino referente a si no hay también ideas de lo particular (Enn. v 7) fue especialmente afín al pensamiento de los siglos XIX y XX. Naturalmente, la ciencia natural moderna y su concepto de principio de individuación a través del espacio y del tiempo quedaron en segundo plano en Plotino. Pero esto sí tiene validez para toda la época moderna y, con ello, para el concepto de ser de la ciencia. Esto descaminó la investigación moderna de Platón. Y todavía vale para el prestigioso estudio de Stenzel sobre la "areté" y la "diairesis" y para la perspectiva general que él agregó. Él empleó todo un capítulo de su obra juvenil revolucionaria para señalar como meta de la diairesis el ótouov cĩos en una forma que correspondió

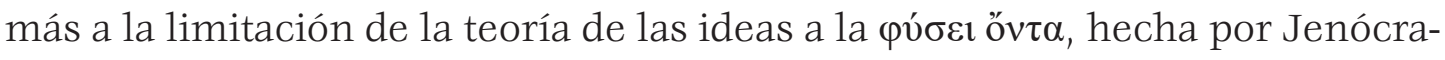
tes y Aristóteles. De manera muy similar se entendió también, en la investigación moderna, la relación de la Politeia con los Nomoi, interpretando los libros sobre las Leyes como una adaptación a la realidad - aunque esta adaptación, si uno así la piensa, no llega, de manera convincente, muy lejos.

En forma muy parecida se presentó después la imagen que surgió del desarrollo de Aristóteles y que fue delineada por Hermann Usener y después por Werner Jaeger. Según ello, Aristóteles al principio todavía fue un platónico y se adhirió a la teoría de las ideas, hasta que paulatinamente llegó a ser un investigador empírico. Este esquema sigue, en realidad, la analogía natural a las ciencias empíricas, las cuales rigen el pensamiento de la ciencia contemporánea. Por principio, incluso después de descartar el esquema de Jaeger, aún no 
se reconoce, de ninguna manera, su inconveniencia básica. A mi juicio, el diálogo Parménides es el documento irrefutable en donde se evidencia que Platón consideró un sinsentido el problema de la participación de lo particular en la idea. De forma que él declaró a la [345] dialéctica como la portadora misma del proceso filosófico, precisamente, porque ella se mueve en la dimensión del eidos y de las relaciones eidéticas, a saber, de las relaciones de las ideas entre sí. Pero esto incluye que no es la separación de la idea de lo particular, sino sólo el vínculo de las ideas entre sí, el que integra el saber y el conocimiento. El real sentido del "chorismos" es la separación entre el saber y la contingencia de las experiencias inciertas. Tan sólo porque la idea del calor está ligada, esencialmente, con la del fuego, la nieve no puede nunca resistir la presencia del calor y del fuego sin que ella se derrita como se concluye en el Fedón. Sobre esta base, en el Fedón se llega a la conclusión de la unión esencial del alma y de la vida y la exclusión de la muerte y, con ello, se sustenta la prueba de la inmortalidad del alma - del alma de este hombre aquí (i!)—. Éstos son, en primer lugar, los auténticos pasos del conocimiento. La mera suposición del eidos como tal es, como ya lo aprendimos en el Fedón, un simple hecho. Ella es, por cierto, un prerrequisito para todo conocimiento real, pero ella misma no lo es. Si uno considera esto en toda su dimensión, entonces el giro tardío de los Diálogos eleáticos y la tematización expresa de la diairesis es, en verdad, sólo la consecuencia y elaboración correcta de lo que expresó el giro hacia los logoi y el eidos en el Fedón. En los diálogos Menón y Fedón aparece el giro en la forma mítica de la anamnesis. Ya la introducción de la "anamnesis" en el Menón demuestra que, en el caso de la "anamnesis", se trata de la resistencia al disparate erístico y a tales pseudoargumentos, a través de los cuales se impugna, sin lugar a dudas, la posibilidad de buscar, preguntar y conocer.

También en el Fedón la hipótesis del eidos apunta, como se indicó anteriormente, a que el pensamiento se mantiene en su objetividad en contraposición con todas las artes de enredo sofistas. El pensar no es tan sólo la visión de conjunto de los muchos con vistas a la unidad del eidos que se encuentra en la unidad de significado de las palabras, sino además significa que lo pensado se distingue, de cierta manera, de otra cosa. Con ello está implicada la interdependencia de las ideas. El mal uso erístico de la argumentación consiste, justamente, en la confusión conceptual, consciente o inconsciente. El pensamiento y el uso de la palabra incluyen que uno ve conjuntamente los muchos

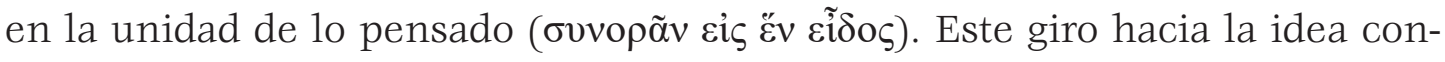


duce, como se muestra en el Fedón, dándole la espalda al laberinto de la multiplicidad empírica, hacia los logoi que desde entonces se llaman dialéctica.

Para el pensamiento de la ciencia moderna, esto implica, ciertamente, una especie de barrera del conocimiento. El conocimiento se limita, aquí, a la relación entre las ideas y la articulación de lo pensado que alcanza, en un último eidos indivisible, la meta del entendimiento, compartida por todos. Esto [346] es, en verdad, la meta-límite a la cual todos nosotros aspiramos frente a la comunidad del mundo interpretado. Esto reside en la esencia de la lengua. No soy capaz de ver cómo se puede entender el estado fundamental de la lengua diferente de como lo describió Platón: una relación entre las ideas. Esto puede sonar "idealista". Pero la sustitución del eidos o de la unidad concreta de 1o pensado por el concepto de la regla y su aplicación, uso que se hace valer en contraposición, me parece, tan sólo, otra manera de describir el mismo giro eidético que todos nosotros, en verdad, realizamos, aunque únicamente utilicemos signos o abramos la boca. Lo que se quiere rechazar en la teoría científica moderna como "idealismo" o como "esencialismo" es concebido desde el concepto moderno de la ciencia. Pero el propósito de Platón y Aristóteles tiene una relevancia fundamentalmente diferente en las "vivencias". Con ellos, el conocimiento no pretende ser un conocimiento en el sentido del mando que domina un ámbito de la experiencia. Más bien, es un conocimiento del orden que sabe que en los sucesos surgen el desorden y la contingencia ingobernable, de forma que todo lo así denominado conocimiento tiene límites diferentes de la experiencia. En el pasaje decisivo de la República platónica donde se habla del descenso que emana del inicio sin supuestos, este descenso no ter-

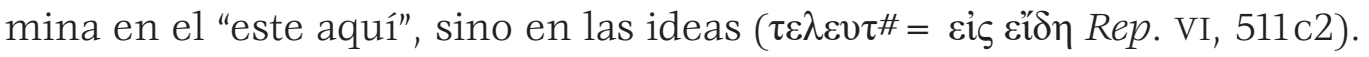

Si se entiende el suceso del diálogo que se presenta en el Sofista, en el sentido de esta finalidad del conocimiento, inmediatamente salta a la vista que la dialógica socrática se perfecciona en la dialéctica platónica. El diálogo Parménides se lee, en este sentido, ya como una especie de autocrítica eleática. Ésta permea la unidad latente de los eléatas con el joven Sócrates y con la dialéctica platónica. Lo mismo vale para la situación con la cual inicia la conversación en el Sofista entre el Extranjero de Elea y los otros participantes. Ahí, casi al inicio, en la bienvenida al Visitante de Elea se hace sentir el poder demónico de la dialéctica. De hecho, se sabía en Atenas lo que había llegado de la Magna Grecia, si haya sido la retórica de Gorgias o la dialéctica negativa de Zenón que trabajaba con las antítesis que suscitaron la revolución cultural sofista. De manera que, justamente, al inicio del Sofista uno se hace a la idea 
de todo el rigor del tema. ¿Realmente habrá una diferencia entre el sofista y el filósofo?

No ha de extrañarnos el que se vincule con esta pregunta la pregunta por el verdadero político que encontró su desarrollo en el siguiente Diálogo, el Político. En ambos casos puede uno preguntarse: ¿serán todos los dialécticos sofistas y todos los políticos demagogos? En las ciudades-Estado griegas tanto el arte de la conversación como el arte de la discusión desempeñaron un papel político fundamental de forma que uno, realmente [347], debió preguntarse: ¿se trata, en estas artes, en sustancia, de la verdad? ¿No expresa Protágoras con su relativismo pragmático precisamente lo que aconteció en la vida política de aquel entonces y no acudieron los jóvenes ambiciosos justamente a Protágoras porque estas nuevas artes, la retórica y la dialéctica, les prometían éxito político? Así, en Platón, se prueba la ignorancia de los maestros del arte de la elocuencia y en el Gorgias la retórica se desacredita como adulación.

Uno realmente siente estar en otro mundo cuando se trata de un conocimiento genuino y esto se logra, ejemplarmente, en la matemática que en aquel tiempo estaba en auge. El arte del puro hablar por hablar y de la dialéctica vacía pertenecen al mundo de la apariencia. De este modo, no se puede llegar a un fundamento sólido de la verdad porque el oleaje del discurrir inunda todo. Esto debe preguntarse aquel que conoce una ciencia como la matemática, en dónde residirá un saber en tal mero discurrir. Así le sucedió a Teeteto. Él y su maestro, el matemático Teodoro, hicieron caso omiso, debido a la experiencia, de su relación amistosa con Protágoras y del arte del puro hablar para salvarse en la tierra firme del saber matemático. También en el diálogo Parménides no faltan las alusiones respecto a cuán peligroso puede resultar el mal uso de la dialéctica cuando a uno le aturden la oleada de los argumentos.

La presentación que el viejo Parménides realiza en el diálogo platónico todavía hoy en día lo puede ilustrar. ¿Contiene esta dialéctica, realmente, un valor intrínseco? El lector se halla en un completo desamparo. Ciertamente, la interpretación alegórica de la antigüedad tardía de esta dialéctica no la podemos tomar en serio. También el intérprete e investigador moderno tiene sus dudas acerca del sentido de todo esto. ¿Acaso será puro capricho?

Para Platón, habrá sido algo distinto. Esto ya indica la manera respetuosa en la cual son retratados Parménides y Zenón y, particularmente, la benevolencia que ellos muestran de cara al joven Sócrates. Aunque las argumentaciones que Parménides expone parecen muy caprichosas, ciertamente, no hay duda de que se practica, de esta manera, un discurso que deduce un conoci- 
miento de causa. Esto se confirma, expresamente, por el hecho de que el anciano Parménides exhorta y estimula al joven Sócrates a que siga practicando con mucho esmero tales discursos dialécticos, aunque parezcan ser pura char-

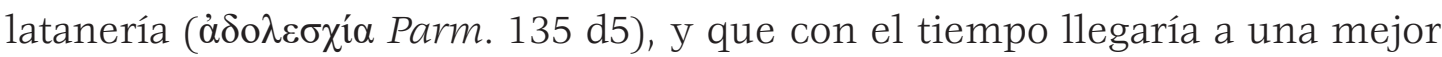
comprensión de la esencia de los logoi.

Éste es el trasfondo de las artes dialécticas ante el cual tiene lugar la conversación acerca del sofista. Cuando Sócrates, al principio, le pregunta al huésped de Elea cómo se piensa en Elea acerca de la diferencia entre el filósofo, el sofista y el político, el fóraneo se presenta bien preparado en relación con esta pregunta. Evidentemente es un arte dudoso [348] de lo que aquí se trata, y se hace, con frecuencia, mal uso de él. La misma pregunta ya estuvo [planteada] tras la conversación entre Sócrates y el joven Teeteto cuando se trató el concepto del saber. En el Sofista, al final de la conversación, emerge, de una manera sobresaliente, cuán cercano se halla el sofista del demagogo (Sofista 268b) y esto conduce hacia el siguiente diálogo acerca del verdadero político. También hay otros indicios de esta índole que permiten conocer el trasfondo general, tales como la pregunta si uno puede cazar a seres domesticados (Sofista 222b). Con esta pregunta se debe pensar tanto en el sofista como en el demagogo. Finalmente, la distinción entre el cazador y el pastor pone en tela de juicio a ambos, tanto al falso dialéctico como al falso político. Es un complejo de relaciones de gran alcance donde se encuentra la distinción entre el sofista y el verdadero dialéctico. Realmente no se trata aquí de juegos vacíos de sagacidad. Es significativo cuando, en la conversación con Sócrates, el joven Teeteto, a pesar de su genio científico, no supo decir lo que en realidad sería el saber auténtico. No es sino hasta la conversación con el Visitante de Elea que conducirá a Teeteto a la evidencia de que en los puros logoi también puede haber un conocimiento auténtico. Por cierto, uno debe estar preparado para que sea una tarea difícil de aclarar, tanto a él (como a nosotros), la diferencia entre el filósofo y el sofista.

Al final uno se percatará de que no habrá, en el sentido esperado, un distintivo fijo, por ejemplo, que una argumentación tiene un contenido filosófico (y eso quiere decir que implica verdad) o si ella genera una mera apariencia de un saber real. Se pondrá de manifiesto que se trata en la diferencia entre el filósofo y el sofista (y por cierto también del político) y de una decisión y de una conducta vitales. Por lo tanto, también en el caso del Sofista es recomendable mantener cierta distancia con respecto a los intereses científico-teóricos de la interpretación de Platón obtenida hasta la fecha. Con ello no se quiere 
infravalorar cuán grandes progresos en la conciencia metódica significa el proceso clasificatorio que conduce a la ordenación de conceptos. Paul Friedländer con razón subrayó el hecho de que incluso el maravilloso logro científico del joven Teeteto (que se menciona en el Teeteto 147d ss.) se basa en el mismo proceso de la clasificación conceptual, y cuánto más es válido para el genio taxonómico de Aristóteles que sus clasificaciones conceptuales son parte de sus obras maestras. Todo ello desempeñó un papel importante para la época del helenismo, aunque los profanos se habrán burlado de ello (como demuestra la comedia). En verdad se debe entender este proceso de la taxonomía conceptual a partir del proceso natural y evidente con el cual cada uno intenta superar la confusión, el enredo y la falsa apariencia. Esto lo conocemos en muchos de los inicios de las conversaciones [349] socráticas que Platón escribió tal y como ahí se hace explícita la tarea de distinguir los conceptos. Por ejemplo, en el Protágoras se inicia la conversación con la pregunta por la unidad y la multiplicidad de las virtudes. Se entiende, en seguida, que no se trata, tan sólo, de una mera clasificación y tampoco de un método científico con el cual la ciencia ordena sus resultados o establece definiciones conceptuales. Aquí se trata de algo que es mucho más profundo y que de la acuñación lingüística de toda la experiencia permea el modo de vivir, y en la totalidad es igual. El diálogo y la diairesis son dos formas ejecutivas de la razón pensante del hombre y de su articulación lingüística. En Platón, ambas ideas se llaman "logoi", el pensar y el hablar donde uno decide sus distinciones. Es el espacio de gran alcance que se abre en la conversación y la lengua y que determina nuestro ser y nuestro modo de proceder. El mero mencionar ya incluye una identificación e igualmente el sentido semántico correspondiente a las palabras. Toda conversación se mueve en el ámbito interrogativo de la distinción que se presenta tanto en las palabras que están disponibles como en aquello que se dice e ilustra con estas palabras. Llama la atención de qué manera, en Platón, se retrata a Pródico como un sofista, quien abunda en distinciones semánticas, pero a quien aun así Platón, en sus Diálogos, trata con cierta benevolencia y le da cierta presencia irónica. Algo de ironía, seguramente, se encuentra también en las distinciones que se presentan en el Sofista. Esto es válido tanto para las palabras sugeridas para tales distinciones como también para las cosas mismas que, así, se aclaran más. Con esto siempre se expresa algo como un saber preliminar. Cuando se trata de determinar o denominar algo uno debe saber qué es lo buscado. Tras toda clasificación de conceptos y cosas está la relación antiquísima entre la pregunta y 
la respuesta, entre la búsqueda y el hallazgo que Sócrates tiene presente en el concepto de anamnesis.

De la misma manera en el Sofista nosotros debemos tomar en consideración los antecedentes que ahí se contrastan en las búsquedas de las definiciones y en las clasificaciones conceptuales. Que la distinción entre el filósofo y el sofista serían un asunto en extremo difícil fue claro desde el inicio y, evidentemente, hay múltiples opciones para efectuar aquí clasificaciones conceptuales. Ahí hay muchos prejuicios y nociones preliminares en juego que evidencian una precomprensión inexacta y precaria. Esto es bastante natural y corresponde a cómo se forman las ideas y cómo se quedan grabadas en la lengua. El sofista es, por lo tanto, un ser difícil de comprender. Pero a todas las ideas acerca del sofista un aspecto les es común, y es que él siempre quiere aparecer como alguien que sabe. Quien quiere llegar a una representación clara a través de una apariencia confusa como, por ejemplo, el matemático, quien está acostumbrado a hacerlo en su ciencia, se dirigirá primero hacia cosas externas, sobre todo en actividades técnicas que son típicas [350] para el sofista. El inteligente conductor Eléata de la conversación sabe qué clase de prejuicios podrán estar presentes en su interlocutor. Para el lector tampoco es menester que la definición paradigmática del pescador con caña ya contenga un tono irónico. A los ojos de un matemático, un sofista profesional realmente es algo como un pescador con caña. Él pesca hombres a quienes les da lecciones de las cuales vive como el pescador pesca peces de los cuales vive. Así, en las conversaciones hay ciertas alusiones ingeniosas. Sin embargo, la configuración del sofista llega al fin a ser cada vez más clara con estos intentos de definición. Pero un rasgo característico en común se manifiesta, a pesar de la multiplicidad cambiante de la apariencia del sofista. Es la antilógica, el talento virtuoso, de encontrar contradicciones y de confundir y refutar al otro. Este rasgo parece, en efecto, común tanto al sofista como al dialéctico al que se denomina filósofo.

Pero, en verdad, ahí existe una diferencia esencial. El sofista entra en escena y se representa como alguien que sabe rebatir todo y quien, por eso, aparece como si supiera todo. No sin firmeza, Teeteto rechaza, decididamente, la pretensión de saber todo que se encuentra en esa actitud (Sofista, 233a). Una persona que posee verdadera sabiduría siempre sabe los límites de su saber. Ésta es una de las condiciones previas con las cuales se conduce el diálogo del Eléata con el joven matemático. Teeteto es una persona que sabe de conocimientos genuinos. Justo esto fue lo que a Sócrates en el Teeteto y aquí al Eléata les 
da motivo para no desairar la doctrina sofística, como lo hace Platón muy a menudo, sino para defender la dialéctica como un saber verdadero. Lo que Platón llamó dialéctica es algo diferente del saber aparente de aquellos que tienen contraargumentos sorprendentes para todo y que, debido a ello, parecen saber todo. Los dos diálogos platónicos, el Teeteto y el Sofista, tienen la función conjunta de manifestar la dialéctica como filosofía.

Nuestras reflexiones nos acercaron, así, al verdadero centro del diálogo. Todavía no parece que en ello se encuentre una dificultad especial, si uno está seguro de que el sofista se distingue del filósofo por el hecho de que aquél pretende solamente un saber aparente mientras que el otro busca un saber verdadero. ¿O es la dialéctica siempre, tan sólo, sofística? Uno no debe imaginarse que rechazar esta cuestión de una manera convincente sea tan sencillo. El diálogo entra, más bien hasta ahora, en su fase crítica. La conducción del alma que el Visitante ejerce aquí con el joven Teeteto es una verdadera obra maestra. Ambos concuerdan en que, aquello que el sofista ostenta, no puede ser un genuino saber. Pero ¿por qué, entonces, estos sofistas generan tal efecto? Esto también se lo preguntará Teeteto, quien en tiempos pasados ya había experimentado este efecto en sí mismo y quien pudo observarlo en los jóvenes a su alrededor (233b). Que ahí no se trata de una verdadera sabiduría es un hecho [351] indiscutible para él (233c). El ejemplo del ilusionista, quien sabe imitar absolutamente todo, aclara la desproporción de la pretensión sofista. Así, es de suponer que se trata del arte de imitar a través del discurso y la argumentación como los espectáculos a la manera de las ferias que engañan a los jóvenes, mientras que les falte experiencia.

Con ello tenemos la palabra clave para la conversación subsecuente. También al joven Teeteto le falta todavía, como él mismo lo sabe, experiencia de la realidad (234e). Por eso, el Visitante Eléata lo quiere acercar más al asunto para que ya no se deje engañar por el prestidigitador, el actor y el imitador. Lo importante es la proximidad a las cosas si se quiere evitar la acción a distancia engañosa. En ello se halla una diferencia decisiva, esto es, entre la imagen que reproduce algo real y una imagen ilusoria. Esto parece ser nuevo para Teeteto (235d4).

Esta diferencia entre la imagen y el simulacro se aclara ahora de una manera concreto-grotesca. Hay esculturas que son a la medida $\mathrm{y}$, entonces, hay también otras estatuas de tamaño sobrenatural. Para que éstas, para su efecto, parezcan hechas a la medida y correctas, deben ser trabajadas en contraposición con las medidas reales. Las partes que se observan de lejos se deben engrosar 
extremadamente. Podrá quedar en tela de juicio si Platón y también el Visitante de Elea llamarían en serio a tales estatuas imágenes ilusorias. Tal vez se contentarán, a causa de la intención aclaradora, con lo malogrado de las reales medidas estéticas, como Platón 1o hace normalmente, por ejemplo, en la famosa crítica a los poetas. Aquí, el Eléata, en verdad, le exige mucho a Teeteto cuando él incluye la pintura íntegra al arte de las imágenes ilusorias

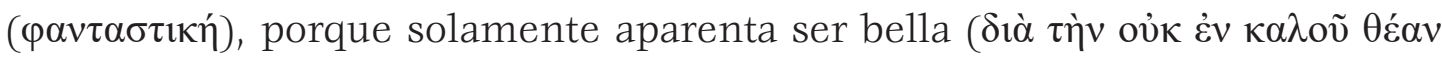
236b4), pero se manifiesta, mirándola con todo detalle, como una apariencia falsa. De todos modos, aquí tenemos que ver con un joven matemático a quien, debido a su propio trato con las figuras, le parece evidente que éstas reproducen estados de cosas matemáticas reales.

De todos modos, sigue siendo peculiar que hasta para el Visitante de Elea mismo quede poco claro si el sofista, a través de su arte, produzca imágenes o simulacros en sus discursos. Esa ambigüedad hará necesario todo el largo camino y rodeo de la conversación y obligará a criticar al "padre" Parménides. Esto se aclarará pronto. ¿No serán todos los puros discursos engañosos, en tanto que ponen ante los ojos algo como presente cuando, en realidad, no está ante los ojos o cuando uno no lo tiene aquí con una evidencia tan concreta

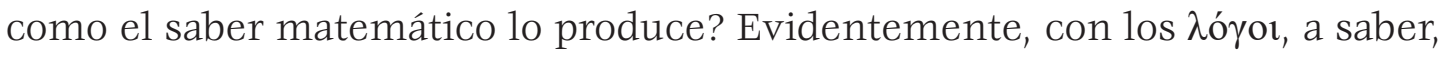
los puros discursos, no es tan fácil constatar y hacer palpable la diferencia entre una imagen real y una que sólo aparenta ser real, [352] como es posible en relación con una estatua. En este caso, uno solamente debe acercarse más a la estatua vista desde lejos para constatar, sin lugar a dudas, la distorsión de la proporción que a mayor distancia simula la impresión correcta. De esta manera se explica por qué hasta el Eléata mismo no está tan seguro si debe contar la conducta del sofista entre el arte de la argumentación que proporciona imágenes reales o el puro arte del simulacro. Teeteto parece ni siquiera conocer otras imágenes más que las hechas a la medida (253e3). ¿Pero incluso si el hecho de producir imágenes siempre se redujera a eso, no será cada cuadro mismo algo diferente de aquello que él imita?

Éste es el problema que aquí constituye la dificultad y esto el Eléata lo señala con insistencia como la posición más fuerte del sofista. Si se quiere seguir al gran Parménides no puede haber ningún no-ser que se pudiera afirmar con sentido. Pero la respuesta a eso que es el "logos" Teeteto la evita. Él no entiende, todavía no, lo que el "logos" realmente es. Cuando el Eléata le muestra que no se puede expresar el no-ser, porque de esta manera no se dice nada, lo toma como el fin ( $\tau \dot{c} \lambda$ os 237e7) de todas las dificultades. Pero, en seguida, el Eléata 
lo conduce hacia una dificultad nueva, todavía mayor. Si el decir no-ser significa no-decir, a saber, no hablar de ninguna manera, entonces, con ello no está asegurado, irrefutablemente, el decir del ser, lo que los eléatas sí hacen. En este punto empieza más bien, como se dice expresamente, la dificultad superior (238a). A lo que es le corresponderá otro ser, pero seguramente no al no-ser.

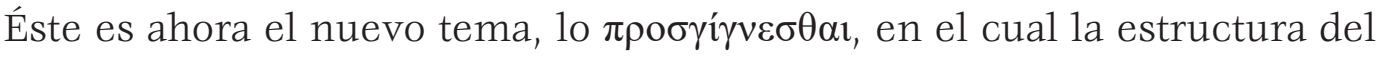
logos surge vagamente por primera ocasión. E1 joven Teeteto lo capta con facilidad porque, ciertamente, está acostumbrado a aproximar los números a lo

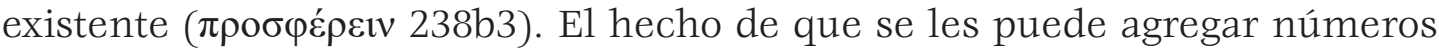
no es válido tan sólo para todo lo existente, sino incluso lo es para los no existentes. ¿Pero, entonces, qué se ganó, en verdad, con la imposibilidad de expresar el no-ser? Hay que repetirlo: Teeteto aún no entiende lo que es el "logos". El nuevo argumento es, a saber, que se debiera aceptar el no-ser en el discurso incluso si se quisiera rechazarlo. Ésta es la cuestión más seria, como 1o expresa el Eléata, porque hace que se terminen todos los argumentos contra el no-ser con un rotundo fracaso (239b). Pero, con ello, el sofista estaría de nuevo a la altura de las circunstancias y podría sentirse seguro con toda clase de afirmaciones, ya que algo como el arte del simulacro o como el no-ser de ninguna manera existirían.

El llamamiento irónico que el Eléata dirige en este pasaje (239d) a Teeteto nos lleva más lejos. En realidad, es una objeción ingenua cuando Teeteto trata de comprobar la realidad de la ilusión al aludir a los espejismos que se dan en la naturaleza y que, en verdad, nada son. La radicalidad de la contraargumentación sofística él, de veras, no la captó. [353] Pero Teeteto ya no puede eludir el aclararse que todos ésos son $\varepsilon \imath \delta \omega \lambda \alpha-\mathrm{y}$ lo que ellos implican (240a ss.) - . E igual pasa con los discursos falsos a cuya apariencia uno sucumbe, como Teeteto lo sabe por experiencia - a pesar de que no se sabe a qué atenerse (240d). Se trata, pues, de que en la imagen, sea lo que sea, el no-ser y el ser están ligados inseparablemente. Pues la imagen no es aquello que tan sólo lo reproduce $\mathrm{y}$, sin embargo, realmente existe lo que denominamos un cuadro. Pero la contraargumentación sofística disputa, justamente, que se pueda pensar y decir algo que no es eso mismo, por lo tanto, el no-ser, y que, por eso, no puede haber una apariencia y una opinión falsa en los $\lambda$ ó yor (241a ss.). Esto es un obstáculo bastante negativo y Teeteto ya no sabe qué hacer. 